\title{
Clastogenic activity of 2-chlorodeoxyadenosine in mammalian somatic cells
}

\author{
Gilmara Ausech Antonucci ${ }^{1}$ and Catarina Satie Takahashi ${ }^{1,2}$ \\ ${ }^{1}$ Universidade de São Paulo, Faculdade de Medicina de Ribeirão Preto, Departamento de Genética, \\ Ribeirão Preto, SP, Brazil. \\ ${ }^{2}$ Universidade de São Paulo, Faculdade de Filosofia Ciências e Letras de Ribeirão Preto, \\ Departamento de Biologia, Ribeirão Preto, SP, Brazil.
}

\begin{abstract}
The base analogue 2-chlorodeoxyadenosine (2-CdA) used for therapy in chronic resistant and advanced lymphoproliferative disorders, is cytotoxic for both dividing and non-dividing lymphocytes. The present work evaluated the clastogenic potential of this drug in vitro in human lymphocytes in culture and in vivo in BALB/c mice bone marrow cells. In human lymphocytes, the clastogenic effect of 2-CdA was studied in G1, S and G2 phases of the cell cycle, using three different concentrations $(10,20$ and $40 \mu \mathrm{g} / \mathrm{mL})$. The endpoints analyzed included mitotic index (MI), proliferation index (PI), sister chromatid exchange (SCE), and chromosomal aberration (CA). Statistical analysis by a variance (ANOVA) test showed a significant increase $(p<0.05)$ in CA frequencies for cells treated during the $\mathrm{S}$ phase, but the MI did not vary. The concentrations tested did not produce a significant increase in the mean frequency of SCEs, nor did they change the cell $\mathrm{PI}$ in the $\mathrm{G} 1$ and $\mathrm{S}$ phases. The concentrations in vivo tested were $0.25,0.375$ and $0.5 \mathrm{mg} / \mathrm{kg}$ body weight. In this assay, alterations in CA frequencies and MI were not observed at the dose levels tested. Therefore, the results indicate a clastogenic effect of 2-CdA in human lymphocyte cultures.
\end{abstract}

Key words: human lymphocytes, 2-CdA, chromosomal aberrations, SCE, cell cycle.

Received: August 5, 2004; Accepted: December 12, 2004.

\section{Introduction}

Purine analogues are highly active in the treatment of lymphoproliferative disorders (Pott-Hoeck and Hiddemann, 1995). Cladribine, 2-chlorodeoxyadenosine (2-CdA), is a nucleoside analogue with a halogen atom replaced at position 2 in its purine ring, which confers resistance to deamination by adenosine deaminase (ADA). 2-CdA is a drug of choice in the treatment of hairy cell leukemia, but it is also highly efficient in other low-grade lymphoid malignancies, including chronic lymphocytic leukemia (CLL). The reports in the literature have shown that 2-CdA gives similar complete response $(\mathrm{CR})$ rate and overall response (OR) rate to fludarabine, but the influence of both agents on the survival rates for patients with CLL is still uncertain. The CR rate induced by $2-\mathrm{CdA}$ is significantly higher than in patients treated with conventional chemotherapy (Robak, 2001). 2-CdA is another new chemotherapeutic purine analogue, with specific toxicity to lymphocytes (Schrimer et al., 1997). The cytotoxicity oc-

Send correspondence to Prof. Dr. Catarina Satie Takahashi. Universidade de São Paulo, Faculdade de Filosofia Ciências e Letras de Ribeirão Preto, Departamento de Biologia, Av. Bandeirantes 3900, 14040-901 Ribeirão Preto, SP, Brazil. E-mail: cstakaha@ usp.br. curs in proliferating and quiescent cells, resulting in events such as inhibition of DNA and protein synthesis, as well as induction of apoptosis (Robertsson et al., 1993). Despite the toxicity, good results in therapeutic response have been obtained, and this drug is the main option in tricoleukemia treatment where patients show hairy cell leukemia (HCL) (Tallman et al., 1992; Tallman et al., 1993).

Adenine deoxynucleosides induce apoptosis in quiescent lymphocytes and are useful drugs for the treatment of indolent lymphoproliferative diseases. Several mechanisms have been proposed to explain the toxicity of deoxyadenosine and its analogues in quiescent cells, including the direct binding of dATP to the pro-apoptotic factor Apaf- 1 and the activation of the caspase- 9 and -3 pathways (Genini et al., 2000).

A patient with acute myeloid leukemia treated with 2-CdA and Ara-C presented delayed marrow recovery, sinusitis, and Candida tropicalis sepsis. She developed multisystem organ failure and died 1 month after initiating AML therapy. Post-mortem examination, limited to the chest and abdomen, revealed disseminated candidiasis involving the lungs, heart, liver, kidneys, and spleen (Mathew et al., 2000).

Zwaan et al. (2002) observed that patients with $t(9: 11)$ appeared to be significantly more sensitive than 
other AML patients to the following drugs: cytarabine (median: 2.9-fold), doxorubicin (4.5-fold), mitoxantrone (8.0fold), 2-chlorodeoxyadenosine (10.0-fold).

Nucleoside analogues (NA) such as cytosine arabinoside, fludarabine, cladribine and gemcitabine are essential components of AML (Acute Myeloid Leukemia) induction therapy; they are also efficient to treat lymphoproliferative disorders and have been used in the treatment of some solid tumors. These important compounds share some common characteristics, namely in terms of requiring transport by specific membrane transporters, and metabolism and interaction with intracellular targets. However, they differ with regard to the types of transporters, and their preferential interaction with certain targets that may explain the effectiveness against rapid proliferating tumors (Galmarini et al., 2001).

Considering this information, it is important to assess the clastogenic potential of 2-CdA, on the basis of reports that this drug induces cytotoxicity (Tallman et al., 1992; Tallman et al., 1993) and DNA single-strand breaks (Liliemark and Juliusson, 1994). The purpose of this study was to evaluate the capacity of this chemotherapeutic agent in inducing chromosome damage in human lymphocytes and bone marrow cells of BALB/c mice.

\section{Materials and Methods}

\section{Chemical agent}

The antitumoral 2-chlorodeoxyadenosine [Ortho Biotech Inc., USA, CAS Registry No. (RN): 4291-63-8] was kindly provided by the Chemotherapy Center of Hospital de Clínicas of the Ribeirão Preto School of Medicine (Faculdade de Medicina de Ribeirão Preto - USP) for the in vitro and in vivo experiments.

\section{Human peripheral blood lymphocytes}

Blood samples were obtained from six non-smoking healthy volunteers (three females and three males), aged 25 to 35 years and submitted to treatment during G1, S and G2 phases of the cell cycle, for analysis of chromosome abnormality (CA) and mitotic index (MI). In addition, lymphocytes from three individuals (two females and two males) were used for sister chromatid exchange (SCE) and proliferation index (PI) analysis. Lymphocytes were grown in 78\% RPMI-1640 medium (Sigma Chemical Co., St. Louis, USA) supplemented with $20 \%$ fetal calf serum (Cultilab, Brazil) and added with penicillin $(5 \mu \mathrm{g} / \mathrm{mL})$ and streptomycin $(10 \mu \mathrm{g} / \mathrm{mL})$. Cells were stimulated with $2 \%$ phytohemagglutinin (Life Technologies, Grand Island, NY). For each $5 \mathrm{~mL}$ of culture medium $1 \mathrm{~mL}$ of plasma was added, and the cultures were incubated at $37^{\circ} \mathrm{C}$ for $52 \mathrm{~h}$ for $\mathrm{CA}$ analysis. 2-CdA solutions were diluted in deionized water at the following concentrations: 10,20 and $40 \mu \mathrm{g} / \mathrm{mL}$ culture medium, according to Preston et al. (1987). A negative control was included in all experiments. Slide preparation and staining were performed by standard techniques (Moorhead et al., 1960). Slides for analysis of sister chromatid exchange (SCE) and proliferation index (PI) were obtained from parallel cultures to which 5-Bromo2'-deoxyuridine (Sigma Chemical Co., St. Louis, USA; $10 \mu \mathrm{g} / \mathrm{mL}$ ) was added in addition to 2-CdA. Differential sister-chromatid staining was obtained by the fluorescence plus Giemsa technique, using Hoechst 33258 (Calbiochem - Behring Corp.; $0.05 \mu \mathrm{g} / \mathrm{mL}$ Hank's solution) and 5\% Giemsa (Merck). This method is a modification of those published by Korenberg and Freedlender (1974) and Perry and Wolff (1974). Slides were exposed to white light overnight. Metaphase preparations with $46 \pm 1$ chromosomes were analyzed in a blind test. The chromosomes were drawn schematically for SCE scoring, as well as for CA analysis.

\section{Treatment protocols}

2-CdA treatment of lymphocyte cultures at different phases of the cell cycle

\section{Chromosomal aberrations (CAs)}

After seven hours the initiation of culture (G1 phase), the lymphocyte cultures were treated with $2-\mathrm{CdA}$ for $1 \mathrm{~h}$ at $37{ }^{\circ} \mathrm{C}$ in culture medium without serum. The cells were fixed $52 \mathrm{~h}$ after the initiation of culture. After treatment with 2-CdA, the cells were washed twice in serum-free medium and reincubated in complete medium. For treatment at $\mathrm{S}$ phase, $24 \mathrm{~h}$-cultures were treated with 2-CdA for $6 \mathrm{~h}$. The cells were washed twice in serum-free medium, reincubated in complete medium and fixed after $52 \mathrm{~h}$ of incubation. For G2phase treatment, 69 h-cultures were treated with 2-CdA for $3 \mathrm{~h}$, and the cells were fixed after $72 \mathrm{~h}$ of incubation. Colchicine (Merck $0.016 \%$ ) was added $1.5 \mathrm{~h}$ before fixation. To determine the MI, 1000 cells were scored per culture, and 100 metaphases from each culture were analyzed for CA, totaling 6000 cells and 600 metaphases, respectively, for each treatment.

\section{Sister chromatid exchanges (SCES)}

Lymphocyte cultures from 4 healthy donors (two females and two males) were treated with 5-BrdU $(10 \mu \mathrm{g} / \mathrm{mL})$ in the beginning of incubation, and when cells reached the $\mathrm{G} 1$ phase ( $7 \mathrm{~h}$ after the initiation of culture), 2-CdA plus 5-BrdU was added for $1 \mathrm{~h}$ at $37{ }^{\circ} \mathrm{C}$ in culture medium without serum. After treatment, the cells were washed twice in serum-free medium, 5-BrdU was added again and then the cells were reincubated in complete medium. For treatment in the $\mathrm{S}$ phase, $24 \mathrm{~h}$-cultures were treated with 2-CdA plus 5-BrdU in serum-free medium for $6 \mathrm{~h}$. After the treatment, cells were washed twice in serum-free medium and reincubated in complete medium with 5-BrdU. For SCE and PI analysis, the cells (G1 and S phases) were fixed $72 \mathrm{~h}$ after the initiation of culture. Fifty second-division metaphases per culture were scored for 
SCE, and one hundred metaphases from each culture were scored for first, second and third cell division, totaling 200 metaphases and 400 cells per treatment, respectively. The PI was obtained using the following equation:

$$
\mathrm{PI}=[(\mathrm{M} 3-\mathrm{M} 1)+1]
$$

where M1 and M3 are the numbers of the first and thirddivision metaphases, respectively (Degrassi et al., 1989).

\section{Animals}

The animals used were BALB/c mice (Mus musculus), obtained from the Animal House of School of Medicine of Ribeirão Preto.

\section{In vivo test on Balb/c mice bone marrow cells}

Mice weighing approximately $30 \mathrm{~g}$ (5-6 weeks) were divided into groups of 8 animals ( 4 males and 4 females) and treated by intraperitoneal injection with $0.5 \mathrm{~mL} /$ final volume of 2-CdA solution diluted with distilled water at the following concentrations: $0.25,0.375$ and $0.5 \mathrm{mg} / \mathrm{kg}$ body weight. Twenty-two hours after treatment (i.e., two hours before sacrifice), the mice were injected with $0.3 \mathrm{~mL} /$ final volume of a $1 \%$ colchicine solution (Sigma) and killed by ether inhalation $2 \mathrm{~h}$ later. The negative control group received distilled water $0.5 \mathrm{~mL} /$ final volume/animal, and the positive control group received cyclophosphamide (CP), $25 \mathrm{mg} / \mathrm{kg}$ body wt. Bone marrow preparations for metaphase cells were obtained by the standard technique (Ford and Hamerton, 1956). Slides were analyzed in a blind test and 100 metaphases per animal were drawn schematically. The MI was obtained by counting the number of mitotic cells in 1000 cells analyzed per animal, and 100 cells were scored for CA.

\section{Statistical analysis}

One-way analysis of variance (ANOVA) was performed on the number of abnormal metaphases and total numbers of CA, MI, SCEs, and PI, with calculations of the $P$ values for each phase of the cell cycle. Whenever $p<0.05$ was found, the mean values of each treatment were compared by the Student-Newman Keuls test. The statistical analysis was carried out by using the Sigma Stat (Jandel Corporation) software packages.

\section{Results}

\section{Human lymphocytes}

Peripheral blood lymphocytes were treated with different concentrations $(10,20$ and $40 \mu \mathrm{g} / \mathrm{mL})$ of $2-\mathrm{CdA}$ in the G1, S and G2 phases of the cell cycle. Chromosomal aberrations (CA) and mitotic index (MI) were analyzed in treated lymphocytes from six healthy individuals (three females and three males) (Table 1). For the cells treated during the $\mathrm{S}$ phase, was observed a significant increase in CA frequencies $(p<0.05)$ at all concentrations, as compared to the control frequencies. The most common types of chromosomal aberration observed were chromatid and isochromatid gaps (data not shown) and breaks, followed by double minutes, double fragments, and single fragments. For cells treated during the G1 and G2 phases, the CA frequencies did not show any statistically significant difference between the treated cultures and the control values. Although there was a slight variation for the MI, a statistically significant difference $(\mathrm{p}<0.05)$ was not observed in either of the treatments in relation to the control indexes.

Table 1 - Chromosomal aberrations and mitotic index in human lymphocytes in culture treated with 2-CdA during G1, S and G2 of cell cycle. A total of 100 cells were analyzed per culture and 600 cells per treatment.

\begin{tabular}{|c|c|c|c|c|c|c|c|}
\hline \multirow[t]{2}{*}{ Cell cycle } & \multirow{2}{*}{$\begin{array}{l}\text { 2-CdA } \mu \mathrm{g} / \mathrm{mL} \\
\text { culture }\end{array}$} & \multirow[t]{2}{*}{$\mathrm{MI} \mathrm{X} \pm \mathrm{SD}$} & \multicolumn{3}{|c|}{ Type of chromosome aberration } & \multirow[t]{2}{*}{$\mathrm{CA} / 100$ cells } & \multirow[t]{2}{*}{$\mathrm{CA} /$ cell } \\
\hline & & & $\mathrm{B}^{\prime}$ & $\mathrm{B}^{\prime \prime}$ & Others & & \\
\hline \multirow[t]{4}{*}{ G1 } & Control & $3.47 \pm 1.25$ & 8 & 1 & $2^{\mathrm{df}} ; 1^{\mathrm{min}} ; 1^{\mathrm{su}}$ & 4.85 & 0.02 \\
\hline & 10 & $2.67 \pm 1.41$ & 3 & 1 & $2^{\mathrm{df}} ; 2^{\mathrm{fs}} ; 1^{\mathrm{dm}} ; 1^{\mathrm{min}} ; 1^{\mathrm{su}}$ & 4.10 & 0.01 \\
\hline & 20 & $2.62 \pm 0.93$ & 9 & 0 & $1^{\mathrm{dm}}$ & 3.73 & 0.01 \\
\hline & 40 & $2.25 \pm 0.54$ & 9 & 2 & $3^{\mathrm{su}} ; 1^{\mathrm{dm}} ; 1^{\mathrm{df}}$ & 5.97 & 0.02 \\
\hline \multirow[t]{4}{*}{ S } & Control & $2.87 \pm 0.50$ & 5 & 2 & $1^{\text {su }}$ & 2.99 & 0.01 \\
\hline & 10 & $2.03 \pm 1.45$ & 15 & 10 & $1^{\mathrm{min}} ; 4^{\mathrm{df}} ; 8^{\mathrm{sf}} ; 1^{\mathrm{dm}} ; 2^{\mathrm{su}}$ & $15.30^{* * *}$ & 0.06 \\
\hline & 20 & $2.07 \pm 0.99$ & 14 & 11 & $7^{\mathrm{df}} ; 1^{\mathrm{dm}} ; 3^{\mathrm{sf}} ; 3^{\mathrm{min}} ; 1^{\mathrm{tr} .}$ & $14.93^{* * *}$ & 0.06 \\
\hline & 40 & $1.7 \pm 1.14$ & 23 & 18 & $1^{\mathrm{min}} ; 3^{\mathrm{dm}} ; 7^{\mathrm{df}} ; 2^{\text {dic. }} ; 1^{\text {qr. }} ; 2^{\text {sf }} ; 1^{\text {radial }} ; 1^{\mathrm{ex}}$ & $22.01^{* * *}$ & 0.09 \\
\hline \multirow[t]{4}{*}{$\mathrm{G} 2$} & Control & $4.32 \pm 2.07$ & 4 & 1 & $1^{\mathrm{dm}} ; 2^{\mathrm{su}}$ & 2.99 & 0.01 \\
\hline & 10 & $2.08 \pm 0.51$ & 14 & 1 & $2^{\mathrm{sf}} ; 1^{\mathrm{min}} ; 1^{\mathrm{df}}$ & 7.09 & 0.03 \\
\hline & 20 & $2.83 \pm 1.05$ & 14 & 0 & $4^{\mathrm{df}} ; 3^{\min }$ & 7.84 & 0.03 \\
\hline & 40 & $2.42 \pm 0.62$ & 15 & 2 & $2^{\mathrm{min}} ; 1^{\mathrm{df}} ; 1^{\mathrm{dm}}, 1^{\mathrm{dic}}$ & 8.21 & 0.04 \\
\hline
\end{tabular}

$\mathrm{MI}=$ mitotic index; $\mathrm{B}$ =chromatidic break; $\mathrm{B}$ '= chromosomal break; $\mathrm{CA}=$ chromosomal aberration; $\mathrm{df}=$ double fragment; min. $=$ minute; su=sister union; $\mathrm{dm}=$ double minute; $\mathrm{sf}=$ simple fragment; $\mathrm{tr} .=$ triradial; dic. $=$ dicentric, qr.=quadriradial; ex.= exchange. ${ }^{* * *} \mathrm{p}<0.05$. 
The mean frequencies of sister chromatid exchange (SCE) and proliferation index (PI) were determined in four controls and in lymphocyte cultures treated with 2-CdA during the $\mathrm{G} 1$ and $\mathrm{S}$ phases in cultures harvested after $72 \mathrm{~h}$ (Table 2). The concentrations tested $(10,20$ and $40 \mu \mathrm{g} / \mathrm{mL})$ did not cause any significant increase in the mean frequency of SCEs, nor did they change the cell PI during the G1 and S phases (Table 2).

\section{Balb/c mouse bone marrow system}

$\mathrm{CA}$ and $\mathrm{MI}$ frequencies were analyzed in bone marrow cells from $8 \mathrm{Balb} / \mathrm{c}$ mice ( 4 females and 4 males) after intraperitoneal treatment with $0.25,0.37$ and $0.50 \mathrm{mg} / \mathrm{kg}$ b.w. of 2-CdA (Table 3). In the in vivo assay, 2-CdA did not show cytotoxic effects for any of the tested doses concerning CA frequencies as well as MI values, when all treatment groups were compared. Most aberrations were chromatidtype breaks. No significant difference $(p<0.05)$ was found either among the animals or between males and females for the parameters analyzed.

\section{Discussion}

Over the last few years, several studies have shown the antiproliferative effect of the drugs used in the treatment of lymphoid malignancies. 2-CdA is a base analogue employed in chemotherapy for a particular kind of leukemia, the hairy cell leukemia. There is also some data demonstrating that 2-CdA can be used in combination with other drugs, in the treatment of refractory and recurrent low-grade nonHodgkin's lymphoma (NHL) (Laurencet et al., 1999; Robak et al., 1999). In the present work, a cytogenetic study in vitro was performed to evaluate the clastogenic potential of 2-CdA in human lymphocytes regarding the induction of CA and SCE. According to Moore and Bender (1993), structural CAs may result in loss of chromosomal material. The kind of CA formed depends on the nature of the lesion induced in the DNA and the cell cycle phase during which the cells were exposed (Natarajan et al., 1996).
Lymphocyte cultures were treated with three concentrations of 2-CdA $(10,20$ and $40 \mu \mathrm{g} / \mathrm{mL})$ during different phases of the cell cycle. The clastogenic effect of the drug was demonstrated by the significant increase $(p<0.05)$ in the $\mathrm{CA}$ frequencies for all the concentrations tested during the $\mathrm{S}$ phase of the cell cycle. For treatment during this phase, 2-CdA was left for 6 hours in the cultures. For agents acting during a specific phase of the cell cycle, the sequence of administration may determine the efficacy and toxicity of a combination therapy (Smorenburg et al., 2001).

These results are consistent with those reported by other authors (Carson et al., 1983), suggesting that 2-CdA is incorporated into DNA producing single-strand breaks (SSBs). SSBs can arise both directly, from the disintegration of damaged sugars, or indirectly, via enzymatic cleavage of the phosphodiester backbone. Direct SSBs arise primarily from an attack by free radicals such as reactive oxygen species, whereas indirect SSBs are mainly normal intermediates of DNA base excision repair (BER). SSBs are also the most common lesions induced by exogenous genotoxins such as ionizing radiation, alkylating agents, and the topol poison camptothecin and its anticancer derivatives (Caldecott, 2004).

Some reports show that the base analog needs a longer period of time for phosphorylation to occur (Gandhi et al., 1997). This mechanism may explain the increased frequency of total chromosomal aberrations during the $\mathrm{S}$ phase of the cell cycle. The same mechanism occurs in cells treated with mitomycin C, an S-dependent compound, which requires DNA replication to convert DNA damages into chromosomal aberrations (Evans and Scott, 1964; Traganos et al., 1980). Other antitumoral agents represent the same mechanism and action of 2-CdA, such as fludarabine and 1- $\beta$-D-arabinosylcitosine (ara-C).

Cytotoxic nucleoside analogs have a broad clinical use. They were among the first chemotherapeutic agents used in the treatment of malignant diseases. The anticancer nucleosides include analogs of physiologic pyrimidine and purine nucleosides. These agents act as antimetabolites,

Table 2 - Frequency of SCE and PI in human cultured lymphocytes treated with 2-CdA in the G1 and S cell cycle phase and harvested at 72 h. A total of 200 and 400 cells were analyzed per treatment for SCE and PI, respectively.

\begin{tabular}{lcccccc}
\hline \multirow{2}{*}{$\begin{array}{l}\text { Phase of } \\
\text { cell cycle }\end{array}$} & $\begin{array}{l}2-\mathrm{CdA} / \\
(\mu \mathrm{g} / \mathrm{mL})\end{array}$ & Mean $\pm \mathrm{S} . \mathrm{D}$ & \multicolumn{3}{c}{ N. of metaphases } & \multirow{2}{*}{ P.I } \\
\cline { 4 - 6 } & & & Cycle 1 & Cycle 2 & Cycle 3 & \\
\hline \multirow{3}{*}{ G1 } & Control & $0.60 \pm 0.31$ & 79 & 134 & 187 & 1.27 \\
& 10 & $0.77 \pm 0.40$ & 100 & 142 & 158 & 1.15 \\
& 20 & $0.97 \pm 0.49$ & 110 & 168 & 122 & 1.03 \\
\hline S & 40 & $1.07 \pm 0.43$ & 108 & 169 & 123 & 1.04 \\
& Control & $0.65 \pm 0.37$ & 78 & 140 & 182 & 1.26 \\
& 10 & $0.82 \pm 0.32$ & 95 & 147 & 158 & 1.16 \\
& 20 & $0.85 \pm 0.22$ & 113 & 148 & 139 & 1.07 \\
& 40 & $1.09 \pm 0.37$ & 96 & 201 & 103 & 1.02 \\
\hline
\end{tabular}

$\mathrm{SCE}=$ sister chromatid exchange; $\mathrm{PI}=$ proliferation index; $\mathrm{SD}=$ standard deviation; 2-CdA = 2-chlorodeoxyadenosine. 
Table 3 - MI and CA frequency observed in Balb/c mice bone marrow cells, intraperitoneally treated with 2-chlorodeoxyadenosine (2-CdA) and their respective negative (water) and positive (cyclophosphamide-CP) controls. A total of 1000 cells/animal were analyzed for the MI ( 8000 cells/treatment) and 100 metaphases/animal (800 metaphases/treatment) for CA.

\begin{tabular}{|c|c|c|c|c|c|c|}
\hline \multirow{2}{*}{$\begin{array}{l}\text { 2-CdA treatment } \\
\mathrm{mg} / \mathrm{kg} \text { b.w. }\end{array}$} & \multirow[t]{2}{*}{$\mathrm{MI} \mathrm{X} \pm \mathrm{SD}$} & \multicolumn{3}{|c|}{ Chromosomal aberrations } & \multirow[t]{2}{*}{$\mathrm{CA} / 100$ cells } & \multirow[t]{2}{*}{$\mathrm{CA} /$ cell } \\
\hline & & $\mathrm{B}^{\prime}$ & B” & Others & & \\
\hline control & $2.99 \pm 1.55$ & 7 & 1 & $1^{\text {ex. }} ; 2^{\text {sf }}$ & 2.86 & 0.01 \\
\hline 0.25 & $2.48 \pm 0.91$ & 3 & 0 & $3^{\mathrm{sf}} ; 2^{\mathrm{df}} ; 1^{\mathrm{min}}$ & 2.34 & 0.01 \\
\hline 0.375 & $2.31 \pm 1.42$ & 6 & 1 & $5^{\text {sf }}$ & 3.13 & 0.01 \\
\hline 0.5 & $2.35 \pm 1.32$ & 11 & 0 & $2^{\min } ; 1^{\mathrm{df}} ; 3^{\mathrm{sf}}$ & 4.43 & 0.02 \\
\hline $\mathrm{CP}$ & $0.8 \pm 0.21$ & 319 & 15 & $1^{\text {ring }}$ & 87.23 & 0.04 \\
\hline
\end{tabular}

$\mathrm{MI}=$ index; $\mathrm{B}$ = chromatid breaks; $\mathrm{B}$ " = isochromatid breaks; CA = chromosomal aberrations; ex. = exchange; $\mathrm{sf}=$ single fragment; $\mathrm{df}=\mathrm{double}$ fragment; $\min =$ minute.

competing with natural nucleosides during DNA or RNA synthesis and as inhibitors of key cell enzymes (Szafraniec et al., 2004), are S-specific, and must be phosphorylated to activate triphosphates (Plunkett et al., 1980). During the S phase of the cell cycle, when the genetic material is duplicated by the DNA replication machinery, cells are especially vulnerable to genotoxic insult. While G1 and G2/M checkpoints arrest cell cycle progression at well-defined points through the inhibition of cyclin-dependent kinases, intra-S-phase checkpoints are known to occur at any time within the $S$ phase and involve multiple signaling pathways (Sidorova and Breeden, 2003; Andreassen et al., 2003)

It is very important to analyze the mechanism of drug response during different phases of the cell cycle. The high level of chromosomal lesion may be due to the cytotoxicity of 2-CdA caused by its conversion to 2-CdATP, which induces inhibition of DNA synthesis and DNA repair, involving the enzymes ribonucleotide reductase and DNA polymerases. This compound shows resistance to adenosine deaminase (ADA) activity, which is conferred by a chlorine atom and the replacement of hydrogen at position 2 of the purine ring adenosine (Baltz and Montello, 1993).

SCEs are often considered a parameter for assessing genotoxicity, because their frequency clearly is increased by exposure to many mutagenic and carcinogenic chemicals. In the present experiment, the frequencies of SCEs in cultures treated with 2-CdA presented a slight increase in relation to control cultures. The increase observed during both phases did not vary significantly.

Since many drugs are activated after they are metabolized, in vivo mutagenicity tests are recommended for assessing the clastogenic activity of those compounds requiring metabolic activation. Such an approach also provides similar conditions to those found in humans (Legator and Ward Jr., 1991). Although there are differences between rodents and humans, it is recommended that any assessment should be based on both in vitro and in vivo studies, and not simply on either of them (Huggett et al., 1996).

In the present study, the clastogenic effect of 2-CdA was also analyzed in BALB/c mice bone marrow cells at concentrations of $0.25,0.375$ and $0.5 \mathrm{mg} / \mathrm{kg}$ body weight. The results showed that 2-CdA was not efficient for inducing chromosome aberrations. The lack of effect in vivo can be due to the limited amount of 2-CdA available, because it was donated in diluted conditions. Genotoxic effects of the base analog gemcitabine have been reported in mouse bone marrow cells using the micronucleus and chromosome aberration test systems. Aydemir and Bilaloglu (2003) showed that gemcitabine did not induce any significant CAs and neither cause reduction in MI by a 6-h treatment period at doses of the 2.0, 4.0 and $8.0 \mathrm{mg} / \mathrm{kg}$ b.w., as compared to the negative control; in contrast, the frequency of total CAs was significantly increased by gemcitabine $(\mathrm{p}<0.0001)$ by a $24-\mathrm{h}$ treatment period with the same doses.

In conclusion, 2-CdA showed a clastogenic effect in human lymphocyte cultures treated in vitro during the $\mathrm{S}$ phase of the cell cycle, but not significant clastogenic effect was observed in cells treated during the $\mathrm{G} 1$ and $\mathrm{G} 2$ phases. In the in vivo assay in mice, 2-CdA did not show any clastogenic effect at the dose levels tested.

\section{Acknowledgments}

We are grateful to Prof. Dr. A.T. Natarajan, Dr. Elza T. Sakamoto Hojo and Dr. Lusania G. Antunes for valuable comments on the manuscript and to Mr. Luiz Augusto da Costa Jr., Mr. Silvio A. dos Santos and Ms. Sueli A. Neves for valuable technical assistance. CAPES and FAPESP process n. 99/10643-7 supported this research. The Research Ethics Committee approved the project (Process: CONEP n. 25000.074430/2001-88).

\section{References}

Andreassen PR, Lohez OD and Margolis RL (2003) G2 and spindle assembly checkpoint adaptation, and tetraploidy arrest: Implications for intrinsic and chemically induced genomic instability. Mutat Res 532:245-53.

Aydemir N and Bilaloglu R (2003) Genotoxicity of two anticancer drugs, gemcitabine and topotecan, in mouse bone marrow in vivo. Mutat Res 537:43-51. 
Baltz JK and Montello MJ (1993) Cladribine for the treatment of hematologic malignancies. Clinical Pharmacy 12:805-813.

Caldecott KW (2004) DNA single-strand breaks and neurodegeneration. DNA Repair (Amst) 3:875-82.

Carson DA, Wasson DB, Taetle R and Yu A (1983) Specific toxicity of 2-chlorodeoxyadenosine toward resting and proliferating human lymphocytes. Blood 62:737-743.

Degrassi F, De Salvia R, Tanzarella C and Palitti F (1989) Induction of chromosomal aberrations and SCE by camptothecin, an inhibitor of mammalian topoisomerase I. Mutat Res 211:125-130.

Evans HJ and Scott D (1964) Influence of DNA synthesis on the production of chromatid aberrations by X-rays and maleic hydrazide in Vicia faba Genetics 49:17-38.

Ford CE and Hamerton JL (1956) A colchicine hypotonic citrate squash sequence for mammalian chromosomes. Technol 3:247-251.

Galmarini CM, Mackey JR and Dumontet C (2001) Nucleoside analogues: Mechanisms of drug resistance and reversal strategies. Leukemia 15:875-890.

Gandhi V, Huang P, Chapman AJ, Chen F and Plunkett W (1997) Incorporation of fludarabine and 1-beta-D-arabinofuranosylcytosine 5'triphosphates by DNA polymerase alpha: Affinity, interaction and consequences. Clin Cancer Res 3:1347-1355.

Genini D, Adachi S, Chao Q, Rose DW, Carrera CJ, Cottam HB, Carson DA and Leoni LM (2000) Deoxyadenosine analogs induce programmed cell death in chronic lymphocytic leukemia cells by damaging the DNA and by directly affecting the mitochondria. Blood 96:3537-3543.

Huggett AC, Schilter B, Roberfroid M, Antignac E and Koeman JH (1996) Comparative methods of toxicity testing. Food Chem Toxicol 34:183-92.

Korenberg JR and Freedlender EF (1974) Giemsa technique for the detection of sister chromatid exchanges. Chromosoma 48:355-360

Laurencet FM, Zulian GB, Guetty-Alberto M, Iten PA, Betticher DC and Alberto P (1999) Cladribine with cyclophosphamide and prednisone in management of low-grade lymphoproliferative malignancies. Br J Haematol 79:1215-1219.

Legator MS and Ward Jr JB (1991) Use of in vivo genetic toxicity data for risk assessment. Mutat Res 250:457-465.

Liliemark J and Juliusson G (1994) 2-Chloro-2'-deoxyadenosine-clinical, biochemical and pharmacokinetic considerations. Arch Immunol Ther Exp (Warsz) 42:7-10.

Mathew S, Lorsbach RB, Shearer P, Sandlund JT and Raimondi SC (2000) Double minute chromosomes and c-MYC amplification in a child with secondary myelodysplastic syndrome after treatment for acute lymphoblastic leukemia. Leukemia 14:1314-5.

Moore RC and Bender MA (1993) Time sequence of events leading to chromosomal aberration formation. Environ $\mathrm{Mol}$ Mutagen 22:208-213.

Moorhead PS, Nowell PC, Mellman WJ, Battipps DM and Hungerford DA (1960) Chromosome preparation of leukocytes cultured from peripheral blood. Exp Cell Res 20:613616.

Natarajan AT, Balajee AS, Boei JJ, Darroudi F, Dominguez I, Hande MP, Meijers M, Slijepcevic P, Vermeulen S and Xiao Y (1996) Mechanisms of induction of chromosomal aberra- tions and their detection by in situ hybridization. Mutat Res 372:247-58.

Perry PE and Wolff S (1974) New Giemsa method for differential staining of sister chromatids. Nature 251:156-158.

Plunkett W, Chubb S, Alexander L and Montgomery JA (1980) Comparison of the toxicity and metabolism of $9-\beta-\mathrm{D}-$ arabinofuranosyl-2-fluoroadenine and 9- $\beta$-D-arabinofuranosyladenine in human lymphoblastoid cells. Cancer Res 40:2349-55.

Pott-Hoeck C and Hiddemann W (1995) Purine analogs in the treatment of low-grade lymphomas and chronic lymphocytic leukemias. Ann Oncol 6:421-433.

Preston RJ, Dean BJ, Galloway S, Holden H, McFee AF and Shelby M (1987) Mammalian in vivo cytogenetic assays. Analysis of chromosome aberrations in bone marrow cells. Mutat Res 189:157-65.

Robak T (2001) Cladribine in the treatment of chronic lymphocytic leukemia. Leuk Lymphoma 40:551-564.

Robak T, Góra-Tybor J, Urbanska H and Krikowski E (1999) Combination regimen of 2-chlorodeoxyadenosine (cladribine), mitoxantrone and dexamethasone (CMD) in treatment of refractory and recurrent low-grade non-Hodgkin lymphoma. Leuk Lympho 32:359-363.

Robertsson LE, Chubb S, Meyn RE, Story M, Ford R, Hitelman WN and Plunkett W (1993) Induction of apoptosis cell death in chronic lymphocytic leukemia by 2-chloro-2'-deoxyadenosine and 9- $\beta$-D-arabinosyl-2-fluoradenine. Blood 81:143-150.

Schrimer M, Mur E, Pfeiffer KP, Thaler J and Konwalinka G (1997) The safety profile of low-dose cladribine in refractory rheumatoid arthritis. A pilot trial. Scand J Rhematol 26:376-379.

Sidorova JM and Breeden LL (2003) Precocious G1/S transitions and genomic instability: The origin connection. Mutat Res 532:5-19.

Smorenburg CH, Sparreboom A, Bontenbal M and Verweij J (2001) Combination chemotherapy of the taxanes and antimetabolites: Its use and limitations. Eur J Cancer 37:2310-23.

Szafraniec SI, Stachnik KJ and Skierski JS (2004) New nucleoside analogs in the treatment of hematological disorders. Acta Pol Pharm 61:223-32.

Tallman MS, Hakimian D, Hogan D and Petersen L (1993) 2-Chlorodeoxyadenosine in the treatment of hairy cell leukemia (HCL): Detection of minimal residual disease (MRD) by immunostaining (IS). Presented at the $8^{\text {th }}$ Symposium on the Molecular Biology of Hematopoiesis in Basel, July 9-13.

Tallman MS, Hakimian D, Variakojis D, Koslow D, Sisney GA, Rademaker AW, Rose E and Kaul K (1992) A single cycle of 2-chlorodeoxyadenosine results in complete remission in the majority of patients with the hairy cell leukemia. Blood 80:2203-2209.

Traganos F, Staiano-Coico L, Darzynkiewicz Z and Melamed MR (1980) Effects of ellipticine on cell survival and cell cycle progression in cultured mammalian cells. Cancer Res 40:2390-2399.

Zwaan MC, Kaspers GJL. Pieters R, Hählen K, Huismans DR, Zimmermann M, Harbott J, Slater RM, Creutzig U and Veerman AJP (2002) Cellular drug resistance in childhood acute myeloid leukemia is related to chromosomal abnormalities. Blood 100:3352-3360.

Associate Editor: Carlos F. M. Menck 